NASA/TM-2003-212206

\title{
Catalyzed Ignition of Bipropellants in Microtubes
}

\author{
Steven J. Schneider
}

Glenn Research Center, Cleveland, Ohio

George A. Boyarko and Chih-Jen Sung

Case Western Reserve University, Cleveland, Ohio 
Since its founding, NASA has been dedicated to the advancement of aeronautics and space science. The NASA Scientific and Technical Information (STI) Program Office plays a key part in helping NASA maintain this important role.

The NASA STI Program Office is operated by Langley Research Center, the Lead Center for NASA's scientific and technical information. The NASA STI Program Office provides access to the NASA STI Database, the largest collection of aeronautical and space science STI in the world. The Program Office is also NASA's institutional mechanism for disseminating the results of its research and development activities. These results are published by NASA in the NASA STI Report Series, which includes the following report types:

- $\quad$ TECHNICAL PUBLICATION. Reports of completed research or a major significant phase of research that present the results of NASA programs and include extensive data or theoretical analysis. Includes compilations of significant scientific and technical data and information deemed to be of continuing reference value. NASA's counterpart of peerreviewed formal professional papers but has less stringent limitations on manuscript length and extent of graphic presentations.

- TECHNICAL MEMORANDUM. Scientific and technical findings that are preliminary or of specialized interest, e.g., quick release reports, working papers, and bibliographies that contain minimal annotation. Does not contain extensive analysis.

- CONTRACTOR REPORT. Scientific and technical findings by NASA-sponsored contractors and grantees.
- CONFERENCE PUBLICATION. Collected papers from scientific and technical conferences, symposia, seminars, or other meetings sponsored or cosponsored by NASA.

- SPECIAL PUBLICATION. Scientific, technical, or historical information from NASA programs, projects, and missions, often concerned with subjects having substantial public interest.

- TECHNICAL TRANSLATION. Englishlanguage translations of foreign scientific and technical material pertinent to NASA's mission.

Specialized services that complement the STI Program Office's diverse offerings include creating custom thesauri, building customized databases, organizing and publishing research results ... even providing videos.

For more information about the NASA STI Program Office, see the following:

- Access the NASA STI Program Home Page at http://www.sti.nasa.gov

- E-mail your question via the Internet to help@sti.nasa.gov

- Fax your question to the NASA Access Help Desk at 301-621-0134

- Telephone the NASA Access Help Desk at 301-621-0390

- Write to:

NASA Access Help Desk

NASA Center for AeroSpace Information 7121 Standard Drive

Hanover, MD 21076 
NASA/TM-2003-212206

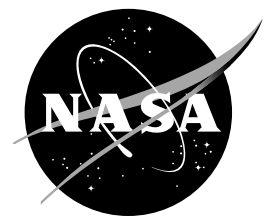

\section{Catalyzed Ignition of Bipropellants in Microtubes}

Steven J. Schneider

Glenn Research Center, Cleveland, Ohio

George A. Boyarko and Chih-Jen Sung

Case Western Reserve University, Cleveland, Ohio

Prepared for the

41st Aerospace Sciences Meeting and Exhibit

sponsored by the American Institute of Aeronautics and Astronautics

Reno, Nevada, January 6-9, 2003

National Aeronautics and

Space Administration

Glenn Research Center 


\section{Acknowledgments}

This work was partially funded by the third Generation LV Program, Propulsion Research and Technology.

Available from

NASA Center for Aerospace Information 7121 Standard Drive

Hanover, MD 21076
National Technical Information Service 5285 Port Royal Road Springfield, VA 22100

Available electronically at http:/ /gltrs.grc.nasa.gov 


\title{
Catalyzed Ignition of Bipropellants in Microtubes
}

\author{
Steven J. Schneider* \\ National Aeronautics and Space Administration \\ Glenn Research Center \\ Cleveland, Ohio 44135
}

\author{
George A. Boyarko ${ }^{\dagger}$ and Chih-Jen Sung \\ Case Western Reserve University \\ Cleveland, Ohio 44106
}

\begin{abstract}
This paper addresses the need to understand the physics and chemistry involved in propellant combustion processes in micro-scale combustors for propulsion systems on micro-spacecraft. These spacecraft are planned to have a mass less than 50 kilograms with attitude control estimated to be in the 10 milli-Newton thrust class. These combustors are anticipated to be manufactured using Micro Electrical Mechanical Systems (MEMS) technology and are expected to have diameters approaching the quenching diameter of the propellants. Combustors of this size are expected to benefit significantly from surface catalysis processes. Miniature flame tube apparatus is chosen for this study because microtubes can be easily fabricated from known catalyst materials and their simplicity in geometry can be used in fundamental simulations to more carefully characterize the measured heat transfer and pressure losses for validation purposes. Experimentally, we investigate the role of catalytically active surfaces within 0.4 and $0.8 \mathrm{~mm}$ internal diameter micro-tubes, with special emphases on ignition and extinction processes in fuel rich gaseous hydrogen and gaseous oxygen. Flame thickness and reaction zone thickness calculations predict that the diameters of our test apparatus are below the quenching diameter of the propellants in sub-atmospheric tests. Temperature and pressure rises in resistively heated platinum and palladium microtubes are used as an indication of exothermic reactions. Specific data on mass flow versus preheat temperature required to achieve ignition are presented.
\end{abstract}

\section{Introduction}

In recent years, there has been a tendency toward shrinking the size of spacecraft. New classes of spacecraft called micro-spacecraft have been defined by their mass, power, and size ranges [1]. Spacecraft in the range of 20 to $100 \mathrm{~kg}$ represent the class most likely to be utilized by most "small sat" users in the near future. There are also efforts to develop 10 to $20 \mathrm{~kg}$ class spacecraft for use in satellite constellations. More ambitious efforts will be to develop spacecraft less than $10 \mathrm{~kg}$, in which MEMS fabrication technology is required. These new micro-spacecraft will require new micro-propulsion technology. Although micro-propulsion includes electric propulsion approaches, the focus of this paper is micro- chemical propulsion which requires the development of micro-combustors. As combustors are scaled down, the surface to volume ratio increases. The heat release rate in the combustor scales with volume, while heat loss rate scales with surface area. Consequently, heat loss eventually dominates over heat release when the combustor size becomes smaller, thereby leading to flame quenching. The limitations imposed on chamber length and diameter has an immediate impact on the degree of miniaturization of a micro-combustor. Before micro-combustors can be realized, such a difficulty must be overcome. One viable combustion alternative is to take advantage of surface catalysis.

\footnotetext{
* Aerospace Engineer, On-Board Propulsion Branch, Steven.J.Schneider@grc.nasa.gov, Associate Fellow AIAA.

$\dagger$ Graduate Student, Department of Mechanical and Aerospace Engineering, gab16@po.cwru.edu. Student Member AIAA.

‡ Associate Professor, Department of Mechanical and Aerospace Engineering, cjs15@po.cwru.edu. Senior Member AIAA.
} 
Micro-chemical propulsion for small spacecraft can be used for primary thrust, orbit insertion, trajectory-control, and attitude control. Grouping micro-propulsion devices in arrays will allow their use for larger thrust applications. By using an array composed of hundreds or thousands of micro-thruster units, a particular configuration can be arranged to be best suited for a specific application. Moreover, different thruster sizes would provide for a range of thrust levels (from $\mu N$ 's to mN's) within the same array. Several thrusters could be fired simultaneously for thrust levels higher than the basic units, or in a rapid sequence in order to provide gradual but steady low-g acceleration. These arrays of micropropulsion systems would offer unprecedented flexibility and redundancy for satellite propulsion and reaction control for launch vehicles.

A high-pressure bi-propellant micro-rocket engine is already being developed [2] using MEMS technology. High pressure turbopumps and valves are to be incorporated onto the rocket "chip." High pressure combustion of methane and $\mathrm{O}_{2}$ in a micro-combustor has been demonstrated without catalysis, but ignition was established with a spark. This combustor has rectangular dimensions of $1.5 \mathrm{~mm}$ by $8 \mathrm{~mm}$ (hydraulic diameter $3.9 \mathrm{~mm}$ ) and a length of $4.5 \mathrm{~mm}$ and was operated at $1250 \mathrm{kPa}$ with plans to operate it at 12.7 MPa. These high operating pressures enable the combustion process in these devices, but these pressures are not practical for pressure fed satellite propulsion systems. Note that the use of these propellants requires an ignition system and that the use of a spark would impose a size limitation to this micro-propulsion device because the spark unit cannot be shrunk proportionately with the thruster.

Currently, cold gas and small monopropellant $\mathrm{N}_{2} \mathrm{H}_{4}$ systems represent the state-of-the-art in micropropulsion. It is generally recognized that reducedscale versions of these conventional systems will not be practical for micro-satellites. In addition these propulsion systems will benefit greatly from the use of non-toxic propellants, which will require ignition. Systems fabricated using MEMS technology and catalyzed ignition/combustion are proposed. Once catalyzed ignition is established in a micro-tube, the reacting gases can be used for propulsion in the micro-propulsion device or they can be propagated into the combustion chamber for ignition in larger thrust class rockets. This benefits all rocket propulsion systems through the elimination of high voltage electrical discharges to achieve spark ignition.

Results presented in this paper consist of an experimental evaluation of the minimum catalyst temperature for initiating/supporting combustion in sub-millimeter diameter tubes. The tubes are resistively heated and reactive premixed gases are passed through the tubes. Tube temperature and inlet pressure are monitored for an indication of exothermic reactions and composition changes in the gases.

\section{Flame Characteristics and Quenching Diameter}

Studies of premixed combustion in a tube have shown that if the tube diameter is progressively decreased, the flame eventually cannot propagate $[3,4]$. Thus, the so-called quenching diameter or distance is the critical dimension of the tube below which flame propagation is not possible. This is because diffusion of species and heat transfer from the flame front to the tube wall quenches the reaction. It is noted that wall quenching affects not only flammability limits, but also ignition phenomena $[3,4]$.

Theoretical analysis has shown that the quenching diameter is on the same order as the flame thickness [3]. The flame thickness represents the overall non-equilibrium processes of reaction and diffusion in the flame, and hence provides an indication of the residence time within the flame. Since the flame thickness is inversely proportional to the burning rate, it decreases with increasing burning intensity. As such, nearstoichiometric flames would have a relatively smaller flame thickness as well as quenching distance due to stronger burning intensity.

Spatially resolved profiles of temperature and heat release rate for a freely-propagating $\mathrm{H}_{2} / \mathrm{O}_{2}$ flame in the flame coordinate can be computed using a detailed mechanism of Mueller et al. [5], which is incorporated into the PREMIX Code [6]. PREMIX is a program for modeling steady, laminar, one-dimensional, premixed flames. Calculations were run for freely propagating $\mathrm{H}_{2} / \mathrm{O}_{2}$ premixed flames under adiabatic and non-adiabatic conditions. It should be noted that the fuel rich extinction limit for atmospheric $\mathrm{H}_{2} / \mathrm{O}_{2}$ flames is at an equivalence ratio of $\phi=12$, mixture ratio (oxygen/fuel mass ratio) of $\mathrm{MR}=0.67$, and $\mathrm{a}_{2}$ mole fraction of 0.96 [7]. 
Flames and their characteristic dimensions can be characterized using various methods of analysis. In the first method, we analyze the $\mathrm{H}_{2} / \mathrm{O}_{2}$ flame by plotting its temperature profile in Figure 1 . A flame thickness, $\delta$, can be obtained by calculating the difference between the final and initial temperatures and dividing by the maximum value of the temperature derivative. As expected, $\delta$ increases with increasing equivalence ratio. This is also shown by plotting the temperature derivative in relation to the flame coordinate in Figure 2. A wider thermal structure is produced by mixtures of greater equivalence ratios. A plot of flame thickness as a function of equivalence ratio for atmospheric pressure combustion is given in Figure 3. Since the combustion process explored in this paper is at low pressure in an altitude test facility for rocket engines, the pressure effect on flame thickness is also calculated as a function of equivalence ratio. The flame thickness at a pressure of $34.5 \mathrm{kPa}$ (approximately $5 \mathrm{psia}$ ) is also plotted in Figure 3. It is seen that flame thickness increases with decreasing pressure and the calculated flame thickness at the test pressure of $34.5 \mathrm{kPa}$ and an equivalence ratio of 10 (mixture ratio 0.8 ) is $4 \mathrm{~mm}$, which is greater than the diameter of either the $0.4 \mathrm{~mm}$ Platinum or the $0.8 \mathrm{~mm}$ Palladium micro-tubes used in this catalytic micro-combustion experiment.

In the second method, we define a reaction zone as the full width of the half maximum of the heat release profile. Figure 4 shows the results for two different equivalence ratios with the reaction zone thickness increasing with increasing equivalence ratio. A plot of reaction zone thickness as a function of equivalence ratio for atmospheric pressure combustion is given in Figure 5. The pressure effect on reaction zone thickness is also calculated and shown in Figure 5 as a function of equivalence ratio for $34.5 \mathrm{kPa}$ pressure. At the equivalence ratio of 10 (mixture ratio $=0.8$ ), the reaction zone thickness is $\sim 1 \mathrm{~mm}$ at atmospheric pressure and initial temperature of $300 \mathrm{~K}$ and increases to $\sim 3 \mathrm{~mm}$ when the pressure is reduced to $34.5 \mathrm{kPa}$. Experimental tests in the micro-tubes were run mostly between 1.2 and 0.4 mixture ratios (equivalence ratios of 6.7 to 20 , respectively). At these mixture ratios and the low pressure of the tests the reaction zone thicknesses are greater than the diameter of either the $0.4 \mathrm{~mm}$ Platinum or the
$0.8 \mathrm{~mm}$ Palladium micro-tubes used in this catalytic micro-combustion experiment.

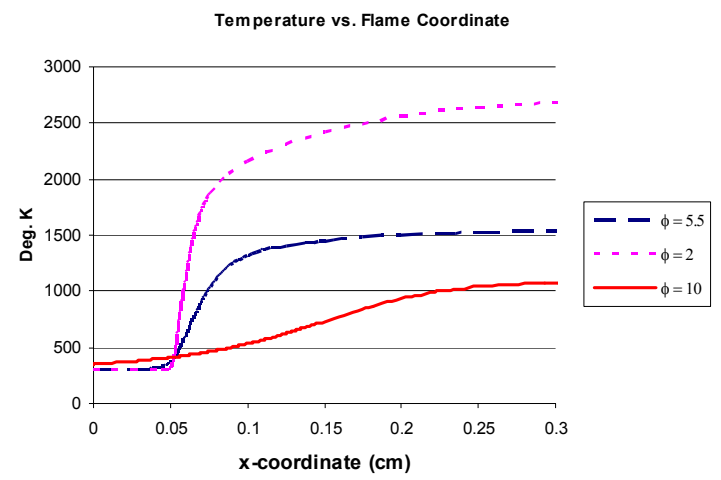

Figure 1. Plot of the temperature versus the flame coordinate for atmospheric $\mathrm{H}_{2} / \mathrm{O}_{2}$ freely propagating flames of three equivalence ratios with an initial temperature of $300 \mathrm{~K}$.

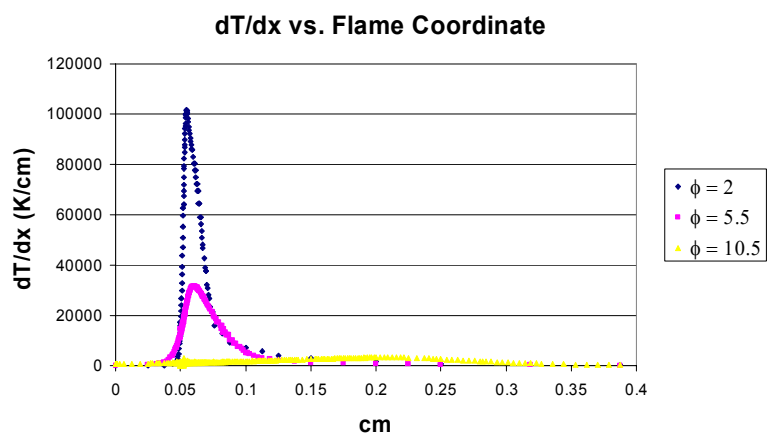

Figure 2. Plot of the temperature gradient versus the flame coordinate for atmospheric $\mathrm{H}_{2} / \mathrm{O}_{2}$ freely propagating flames of three equivalence ratios with an initial temperature of $300 \mathrm{~K}$.

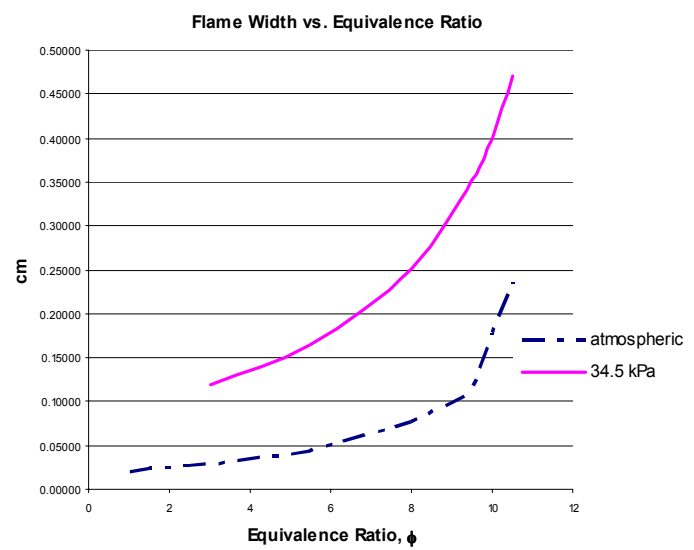

Figure 3. Plot of flame thickness versus equivalence ratio for atmospheric pressure and $34.5 \mathrm{kPa}$. 


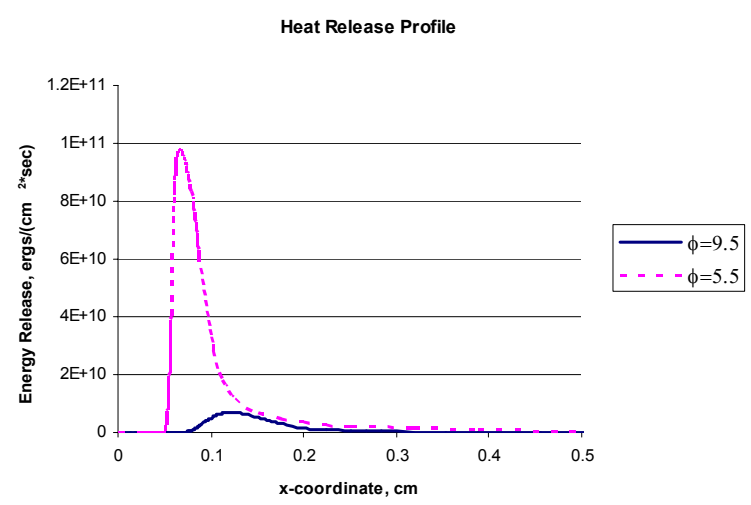

Figure 4. Heat release profile versus the flame coordinate for $\mathrm{H}_{2} / \mathrm{O}_{2}$ flames of two different equivalence ratios at atmospheric pressure.

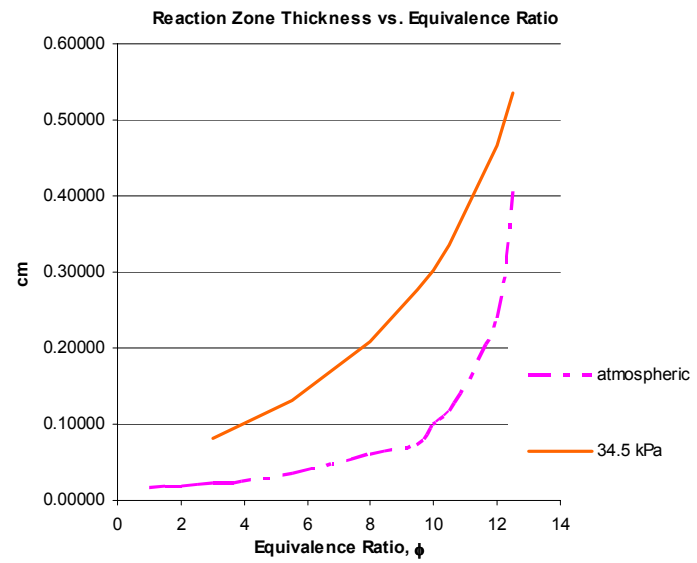

Figure 5. Plot of reaction zone thickness versus equivalence ratio for atmospheric pressure and $34.5 \mathrm{kPa}$. Reaction zone thickness increases with increasing equivalence ratio and increases with decreasing pressure.

In order to determine the flammability limits and capture the extinction turning point, the PREMIX code was modified to include radiative heat loss and the capability of solving the equations at the singular points. When continuing the calculation from the upper (stable) branch to the lower (unstable) branch by passing through the turning point, numerical difficulty, especially with detailed chemistry, is encountered because the Jacobian matrix used in the Newton's method becomes singular at the turning point. To solve this problem, the flame controlling continuation method [8] is employed in this study. Radiative heat loss from $\mathrm{H}_{2} \mathrm{O}$ is considered since it is the primary radiative species in hydrogen flames. The corresponding Planck mean absorption coefficient is a function of temperature and is obtained from Ref. [9]. The analysis was done to test the rich flammability limits of the $\mathrm{H}_{2} / \mathrm{O}_{2}$ flames at low pressure. Figure 6 shows the variation in the mass burning rate with equivalence ratio at pressure of $34.5 \mathrm{kPa}$. It is seen that the burning rate decreases with increasing equivalence ratio. The turning point, beyond which steady flame propagation is not possible, defines the rich flammability limit. Calculations at $34.5 \mathrm{kPa}$ show that the rich limit of the $\mathrm{H}_{2} / \mathrm{O}_{2}$ flame occurs at an equivalence ratio of 12.78, which corresponds to a mixture ratio of 0.626 and a hydrogen mole fraction of 0.962 . We further note that for near rich limit hydrogen flames, in which the Lewis number is greater than unity, pulsating instability has been observed to take place in mixtures with fuel concentrations slightly below that of the rich limit $[7,10,11]$ and the flame is found to oscillatorily extinguish well ahead of the static extinction limit $[10,11]$. Therefore, the flammability range of a $\mathrm{H}_{2} / \mathrm{O}_{2}$ mixture is expected to be narrowed when the intrinsic oscillatory nature of flame propagation is taken into account.

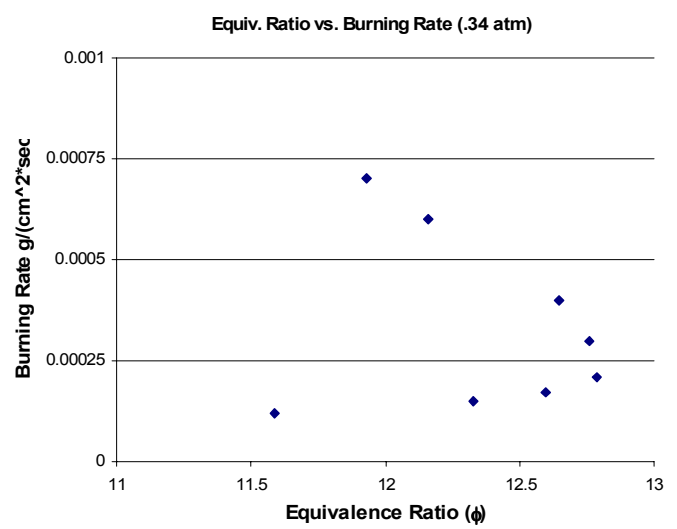

Figure 6. Plot of mass burning rate versus equivalence ratio for $\mathrm{H}_{2} / \mathrm{O}_{2}$ flames at $34.5 \mathrm{kPa}$ (5 psia). The turning point of the response curve defines the rich flammability limit.

\section{Catalytic Combustion}

The principal advantage of using catalysts for primary combustion reactions is their ability to sustain reactions that are well beyond the flammability limit for homogeneous gaseous combustion. During the last three decades, catalysts have been investigated for both augmenting primary heat release in gas turbines and post-combustion treatment of pollutant 
emission in aircraft, automobile, and power generation applications. For generating power, the focus is on conditions at which catalytic reactions are used to promote the primary combustion reactions.

By fundamental definition, a "catalyst" is a substance that alters the reaction rate, while there is no change in its properties or concentration during the catalytic process. In a broader term, the so-called catalyst includes substances that generate catalytic species. A heterogeneous catalyst typically adsorbs the reactants and subsequently promotes critical reactions at certain adsorption sites. Surface reactions occur and then the products are desorbed and along with heat are transported into the flow by diffusion, thereby increasing the overall reaction rate.

Heterogeneous catalyst types can be classified into three types: metals, non-metals (metal oxides and metal sulfides), and salts/acids. The main role of metal catalysts is hydrogenation and dehydrogenation reactions, which generally occur at relatively low or moderate temperatures. Noble metal catalysts or metal oxide catalysts are likely choices for the complete oxidation of an organic compound. Metals are chosen for this study because they can be easily fabricated into microtubes from known catalyst materials and they can be resistively heated. For oxidation reactions, only the noble metals, such as platinum and palladium, retain their integrity for long periods of time. Most metals in high-temperature, oxygen-enriched environments are prone to undergo bulk oxidation or form thick oxide layers on the surfaces.

The reacting flow processes within the catalytic bed are complicated. Take a premixed fuel/air mixture flowing through a long channel with catalytic surfaces as an example [12]. Near the inlet section, the fuel conversion is controlled by the heterogeneous reactions at the surface of the catalyst. In this region, the bulk gas temperatures are typically too low to support homogeneous combustion. After a certain distance downstream of the inlet, the heterogeneous reaction rates increase with increasing temperatures of both near-wall gas and substrate. As the reaction rate increases to an extent, the fuel conversion is no longer controlled by the surface reaction rate. Instead, the fuel consumption is now controlled by the rate at which new gas phase reactants are transported to the surface, and the catalytic reactions at the wall will be limited solely by the rate of mass transfer. Further downstream and beyond this diffusion-limited region, thermal runaway of homogeneous or gas phase reactions occur as heat continues to diffuse into the bulk gas flow. These homogeneous reactions are typically initiated at bulk gas temperatures in the range of 1200 to $1300 \mathrm{~K}$.

Based on the above description, it is imperative to identify how the catalyzed processes scale with the combustor size [13]. In the surface kinetics controlled region, the process is primarily dependent on the catalytic Damköhler number, which is the ratio of system residence time to the characteristic heterogeneous reaction time. For a given residence time, the catalytic Damköhler number is inversely proportional to the combustor size due to the dependence of the heterogeneous reaction rate on surface area. The transition from surface reaction- to diffusion-limited processes and the progression of the latter are expected to scale with the mass transport number that is the ratio of the characteristic residence time of the gas in the reactor to the mass/heat transport time. Since both the heat and mass transfer times scale inversely with the hydraulic diameter, both transport processes are favored when the combustor dimension is reduced, as is the overall progression to the homogeneous reaction region.

Therefore, although the increase of the surface to volume ratio of the combustor is problematic for gas phase combustion, it favors catalytic combustion. Despite the catalytic reaction being generally slower than the gas phase reaction, due to the relative increase of surface area and the lower temperature of the catalytic reaction, microcombustors utilizing catalytic combustion may be easier to implement than those utilizing gas phase reactions. In fact, it has been demonstrated [14] using a heat-recirculating engine that with a catalyst located in the combustion volume hydrogen/air mixtures can exhibit thermal runaway at room temperature and butane (or propane) can self-start at less than $500 \mathrm{~K}$.

Many unique technology issues are related to MEMS-based micro-propulsion systems. They include overall issues such as materials selection, fabrication, sealing, assembly, pressurization, testing, and characterization, as well as the combustion related issues. In view of the above discussion the combustor remains one of the most 
challenging components to miniaturize. Therefore, the fundamental understanding of various microcombustion phenomena constitutes the long range goal of the present study.

The preceding discussion of the physical processes and scaling of catalytic combustion systems, identifies increases in both the heterogeneous Damköhler number and the nondimensional heat and mass transfer rates as combustor size is reduced, resulting in the favorable effects for heterogeneous catalysis due to increased surface-to-volume ratio. These effects can offset the wall quenching effects.

\section{Apparatus and Test Procedures}

Miniature flame tube apparatus is chosen for study because microtubes can be easily fabricated from known catalyst materials and their simplicity in geometry can be used in fundamental simulations to more carefully characterize the measured heat transfer and pressure losses for validation purposes. Experimentally, we investigate the role of catalytically active surfaces within microtubes, with special emphases on ignition and extinction. The experimental apparatus involves the microtube, along with a mass flow control system, electrical power supply to heat a section of tube, and a data acquisition system. A schematic of the instrumented microtubes is shown in Figure 7. Two capillary tubes were available for testing. One was a $0.4 \mathrm{~mm}$ I.D. platinum tube with a $0.15 \mathrm{~mm}$ wall thickness and an overall length of $100 \mathrm{~mm}$ of which $70 \mathrm{~mm}$ was resistively heated. The other tube was $0.8 \mathrm{~mm}$ I.D. and was made of palladium with a wall thickness of $0.1 \mathrm{~mm}$ and an overall length of $190 \mathrm{~mm}$ of which $160 \mathrm{~mm}$ was resistively heated. Three thermocouples were spot welded to the outside of the tubes at the 20,50, and 80 percent positions of the heated section as shown in the schematic. Figure 8 is a picture of the $0.8 \mathrm{~mm} \quad$ I.D. experimental microtube apparatus. The tubes were tested in a small rocket test facility at the NASA Glenn Research Center. The facility maintains an ambient pressure of $1.38 \mathrm{kPa}$ (10 torr) during the tests [15].

These initial tests were conducted with gaseous oxygen and gaseous hydrogen propellants at low mixture ratios (high equivalence ratios) to test the rich flammability limits of the propellants, to avoid melting the catalysts, and to avoid

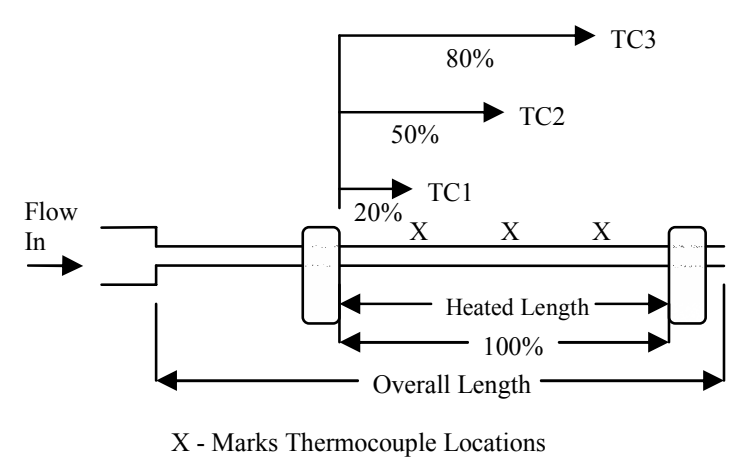

Figure 7. Schematic of microtube test articles.

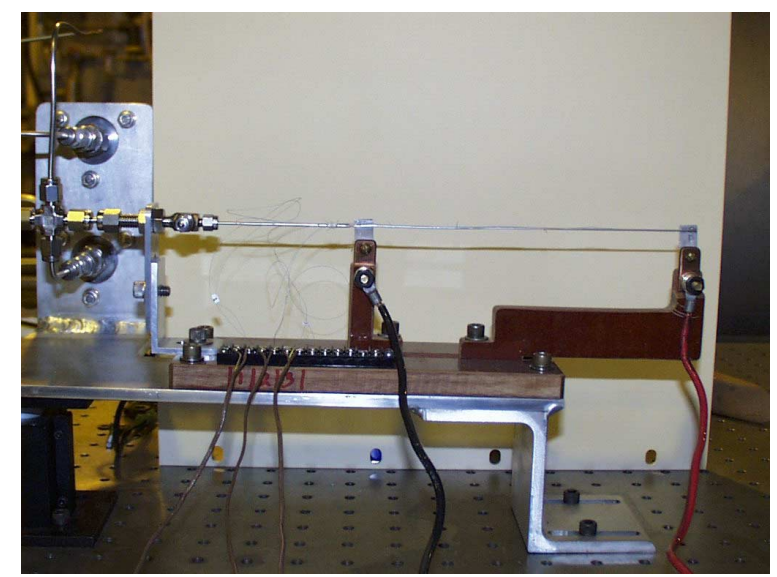

Figure 8. Microtube test apparatus (0.8 mm I.D.).

oxidation loss of catalyst material. These propellants are non-toxic and can be produced onorbit by water electrolysis [16]. They also have detailed gas-phase chemistry, transport properties, and surface kinetics available for numerical simulation.

\section{Results and Discussion}

A Fanno flow calculation was conducted as a first step to assess the effects of friction on the flow velocity in the constant area tubes. A more rigorous Rayleigh-Fanno flow calculation needs to be done in the future to assess the additional effects of resistive heat transfer to the gases and heat release due to reaction in the tube. In order to bound the effects of the change in gas properties on the Fanno flow calculation, flow with both the reactant and equilibrium product properties is evaluated. For example, at a fuel rich mixture ratio of 0.8 the following equilibrium reaction can be written for the propellants

$$
\mathrm{H}_{2}+0.0504 \mathrm{O}_{2} \rightarrow 0.1008 \mathrm{H}_{2} \mathrm{O}+0.8992 \mathrm{H}_{2}
$$


If this reaction goes to equilibrium, the gas temperature rises from 298 to $1100 \mathrm{~K}$ [17], the average molecular weight changes from 3.455 to 3.629 , the viscosity rises from 0.094 to 0.268 millipoise, and the ratio of specific heats changes from 1.405 to 1.353 . This information is used in the Fanno flow calculation for the $0.8 \mathrm{~mm}$ I.D. tube with a measured mass flow of $0.00123 \mathrm{~g} / \mathrm{sec}$. The ambient reactants enter the tube at $48.0 \mathrm{~m} / \mathrm{sec}$ velocity. The flow is laminar at a Reynolds Number of 208 yielding a friction factor of 0.307. This friction factor chokes this flow at the exit of the $190 \mathrm{~mm}$ length of tube. The estimated average residence time of the unreacted gases in the tube would be $0.403 \mathrm{msec}$. In the limit, if the equilibrium products of the reaction are introduced at the entrance of the tube, the inlet velocity could rise up to a maximum of $55.3 \mathrm{~m} / \mathrm{sec}$. The rise in viscosity, however, dominates the Reynolds Number dropping it to 73 and the friction factor increases to 0.876 . With reactions, therefore, the Fanno flow remains choked in the $190 \mathrm{~mm}$ length of tube and the inlet pressure is driven up by the rise in the friction factor.

A Fanno flow calculation for the $0.4 \mathrm{~mm}$ I.D. tube with a measured mass flow of $0.000412 \mathrm{~g} / \mathrm{sec}$ gives an inlet velocity for the unreacted gases of $38.4 \mathrm{~m} / \mathrm{sec}$. The flow is laminar at a Reynolds Number of 140 and the friction factor is 0.459 . Again, with no reactions in the gas, this friction factor chokes the flow at the exit of the $100 \mathrm{~mm}$ length of tube. The estimated average residence time of the unreacted gases in the tube is $0.214 \mathrm{msec}$. In the limit, if the equilibrium products of the reaction are introduced at the entrance of the tube, the inlet gas temperature rises and the inlet velocity could rise up to a maximum of $43.2 \mathrm{~m} / \mathrm{sec}$. The rise in viscosity dominates the Reynolds Number dropping it to 49 and the friction factor increases to 1.31 . With reactions, the flow remains choked in the $100 \mathrm{~mm}$ length of $0.4 \mathrm{~mm}$ I.D. tube and the inlet pressure is again driven up. Actual experimental data with combustion are expected to lie somewhere between these two extremes. This analysis, however, is helpful in evaluating the pressure data.

Experimental results consist of a determination of the minimum catalyst preheat temperature for initiating/supporting combustion in the two submillimeter diameter tubes. Data are obtained with the tubes resistively heated by the power supply in

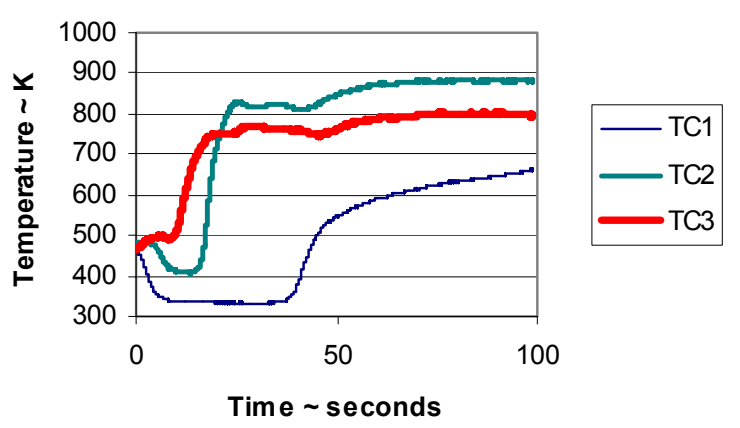

Figure 9. Temperature data for $0.8 \mathrm{~mm}$ I.D. palladium tube, $\mathrm{MR}=0.8,0.00123 \mathrm{~g} / \mathrm{sec}$.

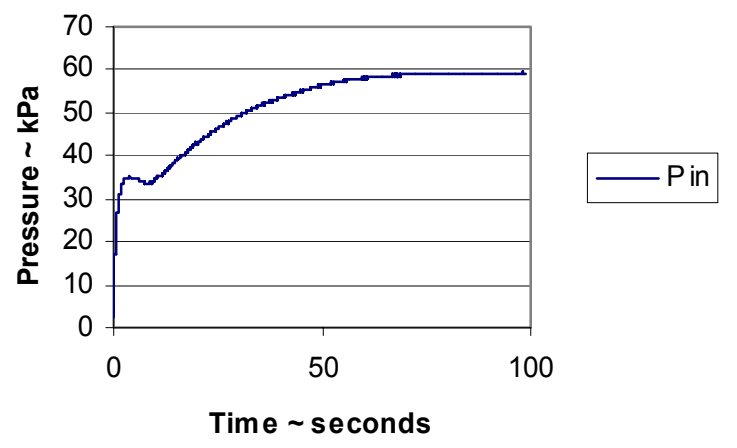

Figure 10. Pressure data for $0.8 \mathrm{~mm}$ I.D. palladium tube, $\mathrm{MR}=0.8,0.00123 \mathrm{~g} / \mathrm{sec}$.

voltage control mode and with reactive premixed gases passed through the tubes. Tube temperature and inlet pressure are monitored for an indication of exothermic reactions and composition changes in the gases.

Temperature data for the $0.8 \mathrm{~mm}$ I.D. tube preheated to a peak temperature of $477 \mathrm{~K}$ and showing an exothermic reaction is given in Figure 9. The total mass flow is $0.00123 \mathrm{~g} / \mathrm{sec}$ of gaseous oxygen and gaseous hydrogen at an oxidizer to fuel mixture ratio of 0.8 (equivalence ratio 9.92). The thermocouples are located as shown in Figure 7. The resistivity of palladium at these temperatures is $17.2 \times 10^{-8} \Omega-\mathrm{m}$ and the voltage drop across the tube is 1.21 Volts, giving an estimated power input of 15 Watts for the deferred Rayleigh-Fanno flow calculation. At 10 seconds into the test TC1 has dropped to $338 \mathrm{~K}$, TC2 has dropped to $412 \mathrm{~K}$ as the gas picks up heat, but TC3 has risen to $511 \mathrm{~K}$ as the gases are heated by catalyzed reactions between TC 2 and TC 3 . At 10 seconds into the test TC3 starts a rapid rise to $750 \mathrm{~K}$. Heat from this reaction is conducted through the tube upstream toward TC2 which starts a rapid temperature rise to $815 \mathrm{~K}$ at 16 seconds 
into the test. Further conduction to the TC1 position is indicated by its rapid temperature rise at 40 seconds into the test. Steady state is reached at TC3 at approximately 60 seconds into the test. The test was terminated at 100 seconds, however, before steady state was reached at TC1.

The pressure in a plenum upstream of the tube is given in Figure 10. The pressure at the start of the test is $2.7 \mathrm{kPa}$ in the altitude test facility. The pressure rises rapidly to $34 \mathrm{kPa}$ at 3 seconds into the test and stays there until about 10 seconds into the test when catalyzed reactions start to drive the pressure up as discussed in the Fanno flow discussion above. The pressure then rises to $59 \mathrm{kPa}$ at 71 seconds into the test and stays there until the test is terminated at 100 seconds. This pressure rise is due primarily to a rise in viscosity and friction factor as the gases are heated by the exothermic reaction. The cold flow pressure predicted by the Fanno Line at the $0.00123 \mathrm{~g} / \mathrm{sec}$ mass flow is $34.9 \mathrm{kPa}$ which agrees with the pressure measured at 3 seconds into the test. If equilibrium combustion were achieved, the Fanno Line would predict a pressure rise to $112 \mathrm{kPa}$, instead of the measured $59 \mathrm{kPa}$.

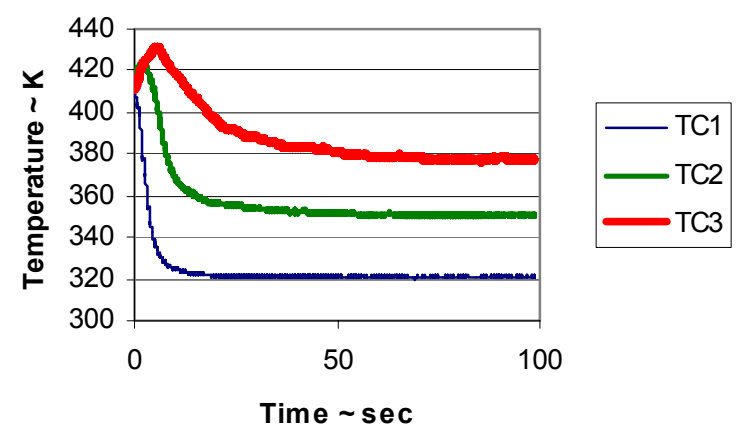

Figure 11. Non-ignition temperature data for $0.8 \mathrm{~mm}$ I.D. palladium tube, $\mathrm{MR}=0.8,0.00123 \mathrm{~g} / \mathrm{sec}$.

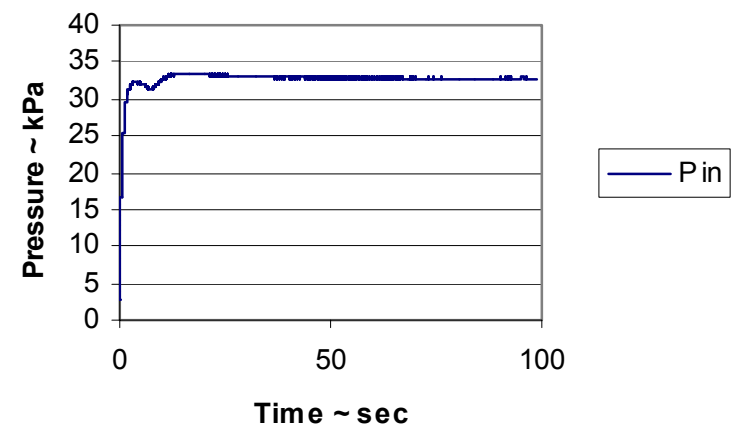

Figure 12. Non-ignition pressure data for $0.8 \mathrm{~mm}$ I.D. palladium tube, $\mathrm{MR}=0.8,0.00123 \mathrm{~g} / \mathrm{sec}$.
Temperature data for the $0.8 \mathrm{~mm}$ I.D. tube preheated to a peak temperature of $422 \mathrm{~K}$ and showing no reaction is given in Figure 11. The total mass flow is $0.00123 \mathrm{~g} / \mathrm{sec}$ of gaseous oxygen and gaseous hydrogen at an oxidizer to fuel mixture ratio of 0.8 (equivalence ratio 9.92). Some reactions between $\mathrm{TC} 2$ and $\mathrm{TC} 3$ cause the temperature of TC3 to rise to a peak of $430 \mathrm{~K}$ at 6 seconds into the test, otherwise all of the temperatures fall to a steady state profile of $\mathrm{TC} 1$ at $321 \mathrm{~K}, \mathrm{TC} 2$ at $351 \mathrm{~K}$ and TC3 at $377 \mathrm{~K}$. The pressure in a plenum upstream of the tube is given in Figure 12 for this case. The pressure rises rapidly and reaches a pressure of $33 \mathrm{kPa}$ at 15 seconds into the test and is in agreement with the cold flow Fanno Line calculation.

Temperature data for the $0.8 \mathrm{~mm}$ I.D. tube preheated to a peak temperature of $589 \mathrm{~K}$ at a mixture ratio of 0.6 (equivalence ratio 13.2) and a mass flow of $0.00160 \mathrm{~g} / \mathrm{sec}$ is given for a reacting case in Figure 13. The corresponding pressure data is given in Figure 14. This equivalence ratio is above the extinction limit predicted by theory. If the preheat temperature is reduced to approximately $530 \mathrm{~K}$, the temperature data shown

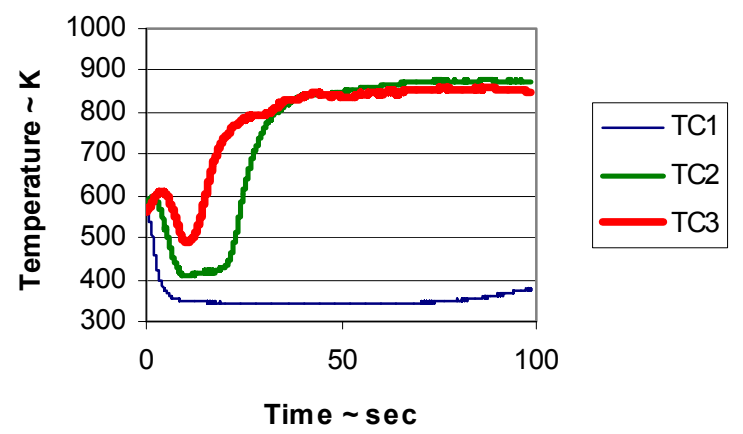

Figure 13. Temperature data for $0.8 \mathrm{~mm}$ I.D. palladium tube, $\mathrm{MR}=0.6,0.00160 \mathrm{~g} / \mathrm{sec}$.

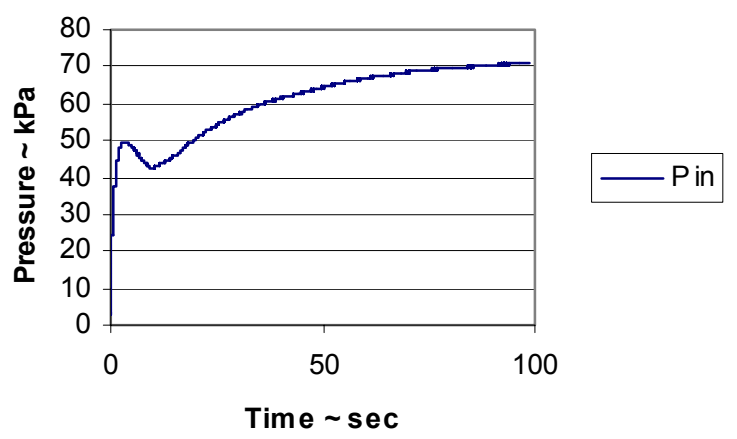

Figure 14. Pressure data for $0.8 \mathrm{~mm}$ I.D. palladium tube, $\mathrm{MR}=0.6,0.00160 \mathrm{~g} / \mathrm{sec}$. 


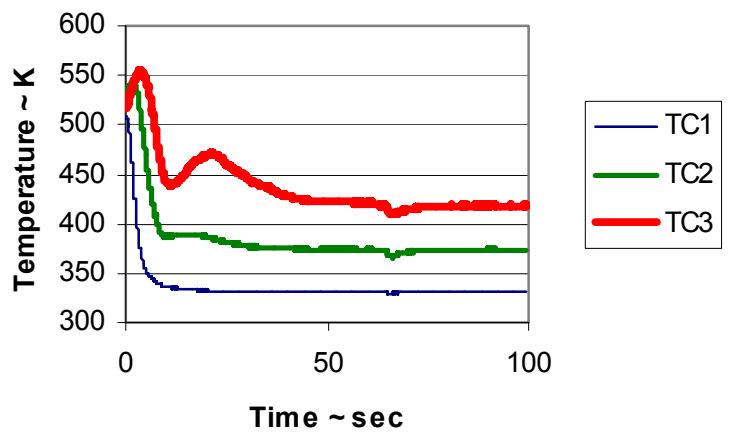

Figure 15. Non-ignition temperature data for $0.8 \mathrm{~mm}$ I.D. palladium tube, $\mathrm{MR}=0.6,0.00160 \mathrm{~g} / \mathrm{sec}$.

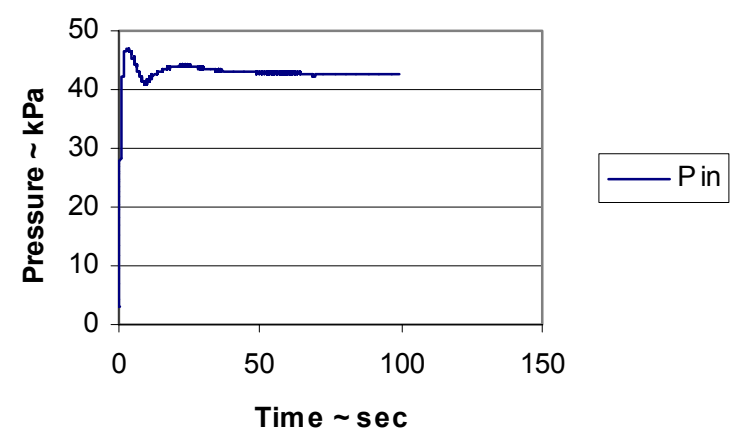

Figure 16. Non-ignition pressure data for $0.8 \mathrm{~mm} \mathrm{I.D.}$ palladium tube, $\mathrm{MR}=0.6,0.00160 \mathrm{~g} / \mathrm{sec}$.

in Figure 15 results indicating that the reactions have not occurred. The corresponding pressure data is shown in Figure 16 and is in agreement with the cold flow Fanno Line calculation at $0.00160 \mathrm{~g} / \mathrm{sec}$ indicating that there are no reactions.

Temperature data for the $0.4 \mathrm{~mm}$ I.D. platinum tube preheated to a peak temperature of $640 \mathrm{~K}$ which shows an exothermic reaction is given in Figure 17. The total mass flow is $0.000412 \mathrm{~g} / \mathrm{sec}$ of gaseous oxygen and gaseous hydrogen at an oxidizer to fuel mixture ratio of 0.8 (equivalence ratio 9.92). The resistivity of platinum at these temperatures is $23.4 \times 10^{-8} \Omega-\mathrm{m}$ and the voltage drop across the tube is 1.41 Volts, giving an estimated power input of 31 Watts for the deferred Rayleigh-Fanno flow calculation. At 30 seconds into the test, the thermocouples have dropped to their minimum values of TC1 at $400 \mathrm{~K}, \mathrm{TC} 2$ at 480 $\mathrm{K}$ and $\mathrm{TC} 3$ at $550 \mathrm{~K}$. The remaining 30 seconds of the test show an exothermic reaction taking place giving a rise in temperature at TC 3 to $650 \mathrm{~K}$ at the end of the test. This test was terminated before steady state was reached. The pressure in a plenum upstream of the tube is given in Figure 18. The

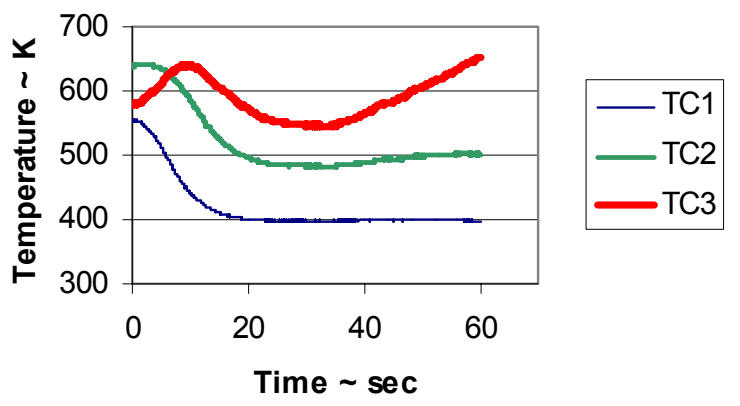

Figure 17. Temperature data for $0.4 \mathrm{~mm}$ I.D. platinum tube, $\mathrm{MR}=0.8,0.000412 \mathrm{~g} / \mathrm{sec}$.

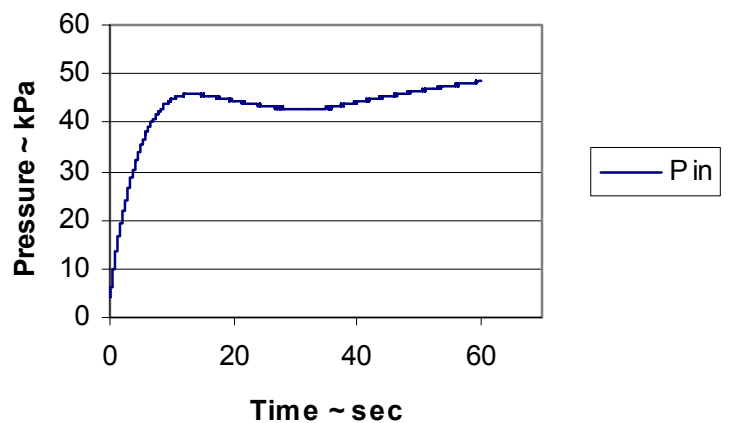

Figure 18. Pressure data for $0.4 \mathrm{~mm}$ I.D. platinum tube, $\mathrm{MR}=0.8,0.000412 \mathrm{~g} / \mathrm{sec}$.

pressure rises to $43 \mathrm{kPa}$ at 30 seconds into the test and then rises to $48 \mathrm{kPa}$ at the end of the test due primarily to a rise in viscosity as the gases are heated by the exothermic reaction.

Temperature data for the $0.4 \mathrm{~mm}$ I.D. tube preheated to a peak temperature of $585 \mathrm{~K}$ which shows only a very mild reaction is given in Figure 19. The total mass flow is $0.000412 \mathrm{~g} / \mathrm{sec}$ of gaseous oxygen and gaseous hydrogen at an oxidizer to fuel mixture ratio of 0.8 (equivalence ratio 9.92). Convection between $\mathrm{TC} 2$ and $\mathrm{TC} 3$ cause the temperature at $\mathrm{TC} 3$ to rise to a peak of $584 \mathrm{~K}$ at 10 seconds into the test, otherwise all of the temperatures fall to a steady state profile of $\mathrm{TC} 1$ at $380 \mathrm{~K}, \mathrm{TC} 2$ at $450 \mathrm{~K}$ and TC3 at $501 \mathrm{~K}$ at 25 seconds into the test and remain these levels except for a slight rise in TC3 until the test is terminated at 69 seconds. The pressure in a plenum upstream of the tube is given in Figure 20 for this case. The pressure at the start of the test is $2.5 \mathrm{kPa}$ and rises rapidly to $43 \mathrm{kPa}$ at 30 seconds into the test as it did in the reacting case shown in Figure 17. The pressure then rises to a plateau of $47 \mathrm{kPa}$ at 65 seconds into the test indicating a mild viscosity change and remains there until the test is terminated at 69 seconds. 


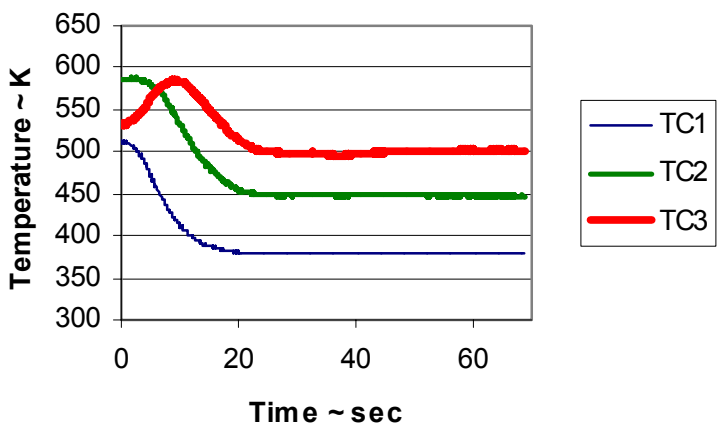

Figure 19. Temperature data for $0.4 \mathrm{~mm}$ I.D. platinum tube, $\mathrm{MR}=0.8,0.000412 \mathrm{~g} / \mathrm{sec}$.

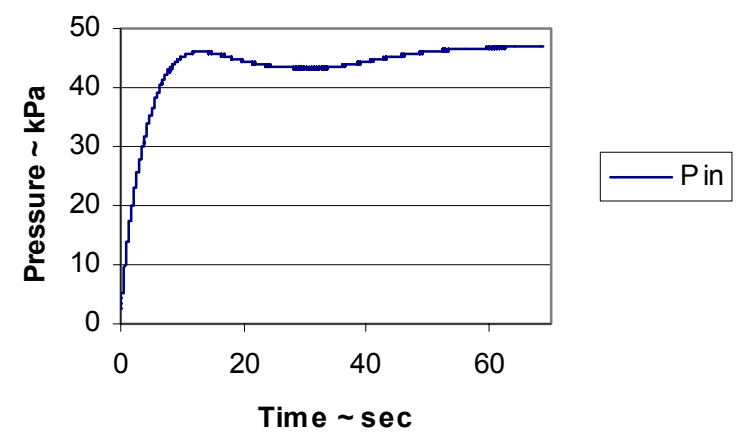

Figure 20. Pressure data for $0.4 \mathrm{~mm}$ I.D. platinum tube, $\mathrm{MR}=0.8,0.000412 \mathrm{~g} / \mathrm{sec}$.

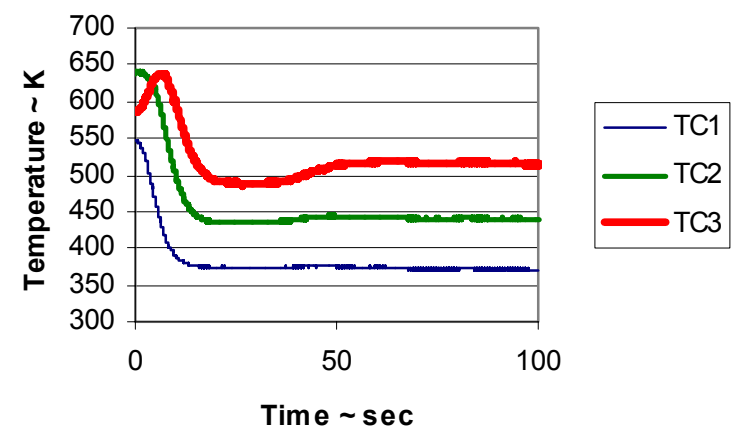

Figure 21. Temperature data for $0.4 \mathrm{~mm}$ I.D. platinum tube, $\mathrm{MR}=0.6,0.000537 \mathrm{~g} / \mathrm{sec}$.

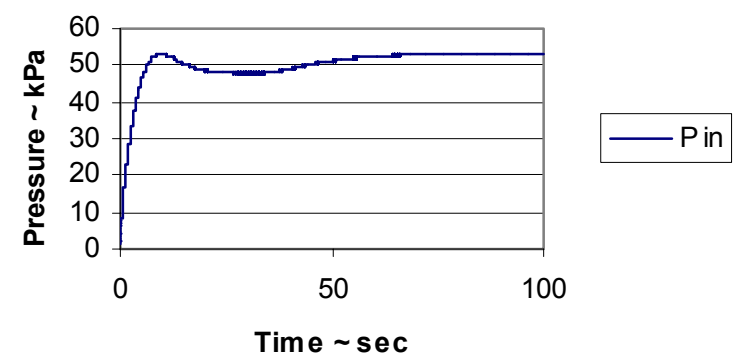

Figure 22. Pressure data for $0.4 \mathrm{~mm}$ I.D. platinum tube, $\mathrm{MR}=0.6,0.000537 \mathrm{~g} / \mathrm{sec}$.

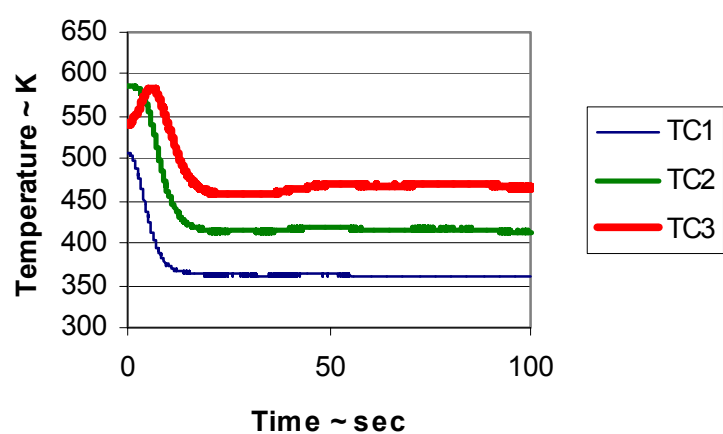

Figure 23. Temperature data for $0.4 \mathrm{~mm}$ I.D. platinum tube, $\mathrm{MR}=0.6,0.000537 \mathrm{~g} / \mathrm{sec}$.

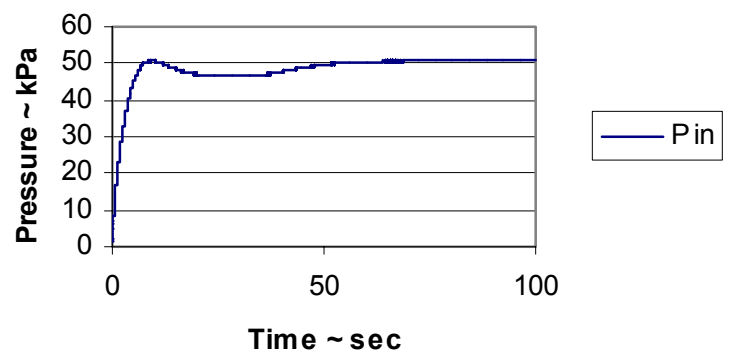

Figure 24. Pressure data for $0.4 \mathrm{~mm}$ I.D. platinum tube, $\mathrm{MR}=0.6,0.000537 \mathrm{~g} / \mathrm{sec}$.

Temperature data for the $0.4 \mathrm{~mm}$ I.D. tube at a mixture ratio of 0.6 (equivalence ratio 13.2) and a mass flow of $0.000537 \mathrm{~g} / \mathrm{sec}$ is given for a reacting case in Figure 21. The peak preheat temperature of $640 \mathrm{~K}$ was used. The corresponding pressure data is given in Figure 22. This equivalence ratio is above the extinction limit predicted by theory. If the peak preheat temperature is reduced to $585 \mathrm{~K}$, the temperature data shown in Figure 23 indicate that less reactions have occurred. The corresponding pressure data is shown in Figure 24.

These data and data at other mass flows and fuel rich mixture ratios are shown on mass flow versus preheat temperature plots in Figure 25 for the $0.8 \mathrm{~mm}$ I.D. palladium tube and Figure 26 for the $0.4 \mathrm{~mm}$ platinum tube. Using temperature and pressure rise as an indication of reactions the solid symbols indicate those test conditions where reactions were observed. As mass flow decreases the preheat temperature required to initiate reactions decreases. For the $0.8 \mathrm{~mm}$ palladium tube the lowest preheat temperature for reactions was $340 \mathrm{~K}$ at a mixture ratio of 0.8 and a mass flow of $0.000128 \mathrm{~g} / \mathrm{sec}$. Above a mass flow of $0.0022 \mathrm{~g} / \mathrm{sec}$ reactions did not occur at any preheat temperature in the $0.8 \mathrm{~mm}$ I.D. palladium tube, $190 \mathrm{~mm}$ long with $160 \mathrm{~mm}$ resistively heated. 


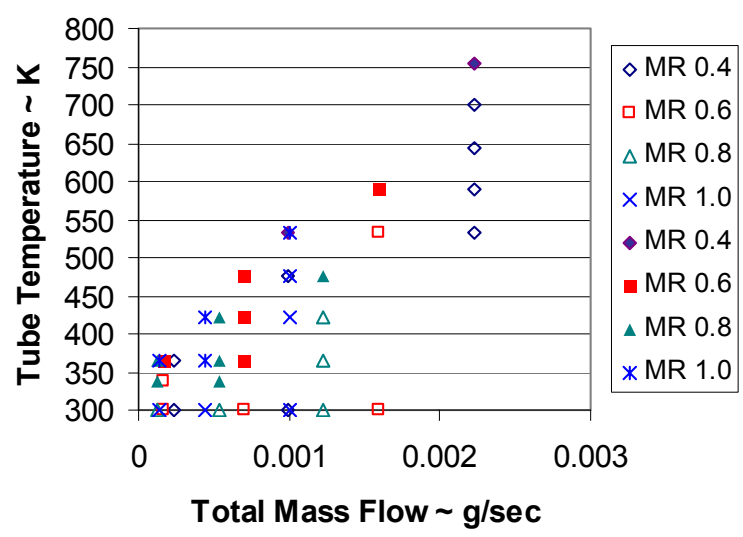

Figure 25. Ignition data for $0.8 \mathrm{~mm}$ I.D. palladium tube - open symbols are non-ignition and solid symbols are ignition as indicated by tube temperature rise.

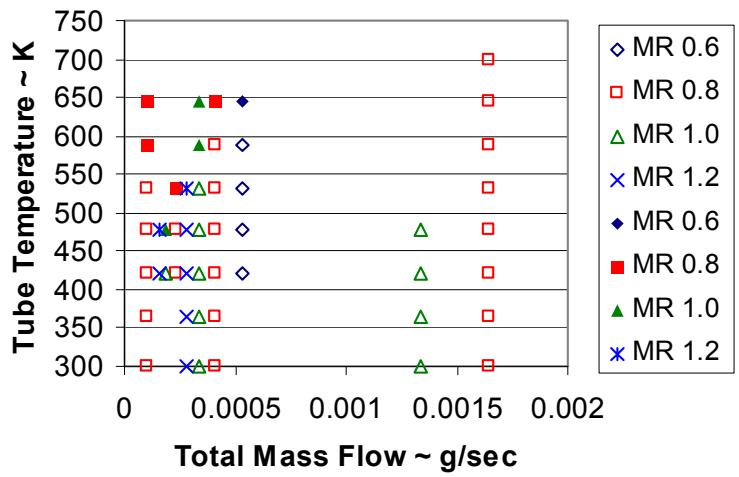

Figure 26. Ignition data for $0.4 \mathrm{~mm}$ I.D. platinum tube open symbols are non-ignition and solid symbols are ignition as indicated by tube temperature rise.

For the $0.4 \mathrm{~mm}$ I.D. platinum tube, the lowest preheat temperature for reactions was $480 \mathrm{~K}$ at a mixture ratio of 1.0 and a mass flow of $0.000187 \mathrm{~g} / \mathrm{sec}$. Above a mass flow of $0.00054 \mathrm{~g} / \mathrm{sec}$ reactions did not occur at any preheat temperature in the $0.4 \mathrm{~mm}$ I.D. platinum tube, $100 \mathrm{~mm}$ long with $70 \mathrm{~mm}$ resistively heated.

\section{Summary}

New micro-spacecraft will require new micropropulsion technology, which will require the development of micro-combustors. The heat release rate in the combustor scales with volume, while heat loss rate scales with surface area. Consequently, heat loss eventually dominates over heat release when the combustor size becomes smaller, thereby leading to flame quenching. The limitations imposed on chamber length and diameter has an immediate impact on the degree of miniaturization of a micro-combustor. One viable combustion alternative is to take advantage of surface catalysis. The favorable effects on surface catalysis associated with the high surfaceto-volume ratio as the combustor size is reduced can offset the wall quenching effects. Flame thickness and reaction zone thickness calculations predict that the diameters of our test apparatus are below the quenching diameter of the gaseous oxygen and gaseous hydrogen propellants in subatmospheric tests.

Miniature flame tube apparatus is chosen for study because micro-tubes can be easily fabricated from known catalyst materials and their simplicity in geometry can be used in fundamental simulations to more carefully characterize the measured heat transfer and pressure losses for validation purposes. A Fanno flow calculation is used to predict the cold flow pressure rise in the tubes, where the experimental mass flow is shown to choke at the exit of the tubes due to friction. Data on the temperature and pressure rise as a function of time in resistively heated platinum and palladium micro-tubes is used as an indication of exothermic reactions in a series of tests varying mass flow, preheat temperature, and fuel rich mixture ratio. As mass flow decreases the preheat temperature required to initiate reactions is shown to decrease.

For the $0.8 \mathrm{~mm}$ palladium tube, $190 \mathrm{~mm}$ long with $160 \mathrm{~mm}$ resistively heated, the lowest preheat temperature for reactions was $340 \mathrm{~K}$ at a mixture ratio of 0.8 and a mass flow of $0.000128 \mathrm{~g} / \mathrm{sec}$. Above a mass flow of $0.0022 \mathrm{~g} / \mathrm{sec}$ reactions did not occur at any preheat temperature in the $0.8 \mathrm{~mm}$ I.D. palladium tube. For the $0.4 \mathrm{~mm}$ I.D. platinum tube, $100 \mathrm{~mm}$ long with $70 \mathrm{~mm}$ resistively heated, the lowest preheat temperature for reactions was $480 \mathrm{~K}$ at a mixture ratio of 1.0 and a mass flow of $0.000187 \mathrm{~g} / \mathrm{sec}$. Above a mass flow of $0.00054 \mathrm{~g} / \mathrm{sec}$ reactions did not occur at any preheat temperature in the $0.4 \mathrm{~mm}$ I.D. platinum tube.

\section{References}

1. Mueller, J., "Thruster Options for Microspacecraft: A Review and Evaluation of Existing Hardware and Emerging Technologies," AIAA 97-3058, 1997.

2. London, A. P., Epstein, A. H., and Kerrebrock, J. L., "High-Pressure Bipropellant Microrocket Engine," Journal of Propulsion and Power, Volume 17, No. 4, pp. 780-787, 2001. 
3. Williams, F. A., Combustion Theory, $2^{\text {nd }}$ edition, Addison-Wesley Publishing Company, Menlo Park, California, 1985.

4. Glassman, I., Combustion, $3^{\text {rd }}$ Edition, Academic Press, San Diego, CA, 1997.

5. Mueller, M. A., Yetter, R. A., and Dryer, F. L., "Flow Reactor Studies and Kinetic Modeling of the $\mathrm{H}_{2} / \mathrm{O}_{2} / \mathrm{NO}_{\mathrm{x}}$ and $\mathrm{CO} / \mathrm{H}_{2} \mathrm{O} / \mathrm{O}_{2} / \mathrm{NO}_{\mathrm{x}}$ Reactions," International Journal of Chemical Kinetics 31, pp. 705-724 (1999).

6. Kee, R. J., Grcar, J. F., Smooke, M. D., and Miller, J. A., A Fortran Program for Modeling Steady Laminar One-Dimensional Premixed Flames, Sandia Report SAND85-8240, 1985.

7. L. He, P. Clavin, "Premixed Hydrogen-Oxygen Flames. Part II: Quasi-isobaric Ignition Near the Flammability Limits," Combustion and Flame 93, pp. 408-420, 1993.

8. Nishioka, M., Law, C. K., and Takeno, T., "A Flame-Controlling Continuation Method for Generating S-Curve Responses with Detailed Chemistry," Combustion and Flame 104, pp. 328342, 1996.

9. Soufiani, A., and Taine, J., "High Temperature Gas Radiative Property Parameters of Statistical Narrowband Model for $\mathrm{H}_{2} \mathrm{O}, \mathrm{CO}_{2}$, and $\mathrm{CO}$ and Correlated k Model for $\mathrm{H}_{2} \mathrm{O}$ and $\mathrm{CO}_{2}$," International Journal of Heat Mass Transfer 40, pp. 987-991, 1997.

10. Christiansen, E. W., Sung, C. J., and Law, C. K., "Pulsating Instability in the Fundamental Flammability Limit of Rich Hydrogen/Air Flames," Proceedings of the Combustion Institute 27, pp. 555-562, 1998.
11. Christiansen, E. W., Law, C. K., and Sung, C. J., "Steady and Pulsating Propagation and Extinction of Rich Hydrogen/Air Flames at Elevated Pressures," Combustion and Flame 124, pp. 35-49, 2001.

12. Groppo, G., Tronconi, E., and Forzatti, P., "Modeling of Catalytic Combustors for Gas Turbine Applications," Catalysis Today 17, pp. 237-250 (1993).

13. Waitz, I. A., Gauba, G., and Tzeng, Y.-S., "Combustors for Micro-Gas Turbine Engines," Journal of Fluids Engineering 120, pp. 109-117 (1998).

14. Maruta, K., Takeda, K., Sitzki, L., Borer, K., Ronney, P. D., Wussow, S., and Deutschmann, O., "Catalytic Combustion in Microchannel for MEMS Power Generation," Third Asia-Pacific Conference on Combustion, Seoul, Korea, June 24-27, 2001.

15. Arrington, L. A. and Schneider, S. J., "Low Thrust Rocket Test Facility", AIAA 90-2503, July 1990.

16. deGroot, W. A. et., al., "Electrolysis Propulsion for Spacecraft Applications," AIAA 97-2948, 1997.

17. McBride, B. J. and Gordon, S., "Computer Program for Calculation of Complex Chemical Equilibrium Compositions and Applications," NASA RP-1311, June 1996. 
Public reporting burden for this collection of information is estimated to average 1 hour per response, including the time for reviewing instructions, searching existing data sources, gathering and maintaining the data needed, and completing and reviewing the collection of information. Send comments regarding this burden estimate or any other aspect of this collection of information, including suggestions for reducing this burden, to Washington Headquarters Services, Directorate for Information Operations and Reports, 1215 Jefferson Davis Highway, Suite 1204, Arlington, VA 22202-4302, and to the Office of Management and Budget, Paperwork Reduction Project (0704-0188), Washington, DC 20503.

\begin{tabular}{|l|l|l}
\hline 1. AGENCY USE ONLY (Leave blank) & $\begin{array}{c}\text { 2. REPORT DATE } \\
\text { February } 2003\end{array}$ & $\begin{array}{r}\text { 3. REPORT TYPE AND DATES COVERED } \\
\text { Technical Memorandum }\end{array}$ \\
\hline
\end{tabular}

\section{TITLE AND SUBTITLE}

Catalyzed Ignition of Bipropellants in Microtubes

\section{FUNDING NUMBERS}

WBS-22-755-04-08

\section{AUTHOR(S)}

Steven J. Schneider, George A. Boyarko, and Chih-Jen Sung

7. PERFORMING ORGANIZATION NAME(S) AND ADDRESS(ES)

National Aeronautics and Space Administration

John H. Glenn Research Center at Lewis Field

Cleveland, Ohio 44135-3191

8. PERFORMING ORGANIZATION REPORT NUMBER

E-13810

\section{SPONSORING/MONITORING AGENCY NAME(S) AND ADDRESS(ES)}

National Aeronautics and Space Administration

Washington, DC 20546-0001

10. SPONSORING/MONITORING AGENCY REPORT NUMBER

NASA TM-2003-212206

AIAA-2003-0674

\section{SUPPLEMENTARY NOTES}

Prepared for the 41st Aerospace Sciences Meeting and Exhibit sponsored by the American Institute of Aeronautics and Astronautics, Reno, Nevada, January 6-9, 2003. Steven J. Schneider, NASA Glenn Research Center; George A. Boyarko and Chih-Jen Sung, Case Western Reserve University, Cleveland, Ohio 44106. Responsible person, Steven J. Schneider, organization code 5430, 216-433-7484.

12a. DISTRIBUTION/AVAILABILITY STATEMENT

12b. DISTRIBUTION CODE

Unclassified - Unlimited

Subject Category: 20

Distribution: Nonstandard

Available electronically at http://gltrs.grc.nasa.gov

This publication is available from the NASA Center for AeroSpace Information, 301-621-0390.

\section{ABSTRACT (Maximum 200 words)}

This paper addresses the need to understand the physics and chemistry involved in propellant combustion processes in micro-scale combustors for propulsion systems on micro-spacecraft. These spacecraft are planned to have a mass less than 50 kilograms with attitude control estimated to be in the 10 milli-Newton thrust class. These combustors are anticipated to be manufactured using Micro Electrical Mechanical Systems (MEMS) technology and are expected to have diameters approaching the quenching diameter of the propellants. Combustors of this size are expected to benefit significantly from surface catalysis processes. Miniature flame tube apparatus is chosen for this study because microtubes can be easily fabricated from known catalyst materials and their simplicity in geometry can be used in fundamental simulations to more carefully characterize the measured heat transfer and pressure losses for validation purposes. Experimentally, we investigate the role of catalytically active surfaces within 0.4 and $0.8 \mathrm{~mm}$ internal diameter micro-tubes, with special emphases on ignition and extinction processes in fuel rich gaseous hydrogen and gaseous oxygen. Flame thickness and reaction zone thickness calculations predict that the diameters of our test apparatus are below the quenching diameter of the propellants in sub-atmospheric tests. Temperature and pressure rises in resistively heated platinum and palladium micro-tubes are used as an indication of exothermic reactions. Specific data on mass flow versus preheat temperature required to achieve ignition are presented.

\section{SUBJECT TERMS}

Chemical propulsion; Rocket engines; Low thrust propulsion; Spacecraft propulsion

\begin{tabular}{|c|c|c|}
\hline $\begin{array}{c}\text { 17. SECURITY CLASSIFICATION } \\
\text { OF REPORT } \\
\text { Unclassified }\end{array}$ & $\begin{array}{c}\text { 18. SECURITY CLASSIFICATION } \\
\text { OF THIS PAGE } \\
\text { Unclassified }\end{array}$ & $\begin{array}{c}\text { 19. SECURITY CLASSIFICATION } \\
\text { OF ABSTRACT } \\
\text { Unclassified }\end{array}$ \\
\hline
\end{tabular}

15. NUMBER OF PAGES 18 16. PRICE CODE 20. LIMITATION OF ABSTRACT 